\title{
Comportamento ingestivo de novilhos de corte em pastagem de aveia preta e azevém com níveis distintos de folhas verdes
}

\author{
Ingestive behaviour of beef steers grazing oat and Italian ryegrass pasture with \\ different levels of green leaves
}

\author{
Naíme de Barcellos Trevisan ${ }^{1}$ Fernando Luiz Ferreira de Quadros ${ }^{2}$ Alexandre Coradini Fontoura da Silva ${ }^{3}$ \\ Duilio Guerra Bandinelli ${ }^{4}$ Carlos Eduardo Nogueira Martins ${ }^{5}$ Luis Felipe Cattani Simões ${ }^{6}$ \\ Adriano Rudi Maixner6 ${ }^{6}$ Dario Rodrigo Fagundes Pires ${ }^{7}$
}

RESUMO

O objetivo deste trabalho foi avaliar como dois níveis distintos de biomassa de folhas verdes, representados por 350 e $600 \mathrm{~kg} \mathrm{ha}^{-1}$ de matéria seca de folhas verdes (MSFV) afetam o comportamento de novilhos de corte $e$ sua taxa de bocados. Para as avaliações de comportamento ingestivo, foi utilizado o método direto de observação visual de animais focais em dois períodos de 24 horas, com início e término às 13:00 horas, durante o ciclo de duração da pastagem, nos dias 16-17/08 e 24-25/09/2002. Para cada turno de seis horas, foram utilizados três observadores treinados, um para cada dois potreiros contíguos (três animais focais por potreiro). A intervalos de 10 minutos eram registrados as atividades de pastejo, ruminação, ócio $e$ realizadas medidas relativas à taxa de bocados, correspondente ao número de bocados de apreensão por minuto. A menor porcentagem de matéria seca existente na pastagem durante a primeira avaliação do comportamento ingestivo foi responsável pelo aumento no tempo de pastejo, na comparação entre períodos. A atividade complementar ao pastejo, na primeira avaliação, foi a ruminação, sem diferenças para ócio. As mais baixas biomassas induziram os animais a aumentar o número de bocados como forma de otimizar o consumo de forragem.

Palavras-chave: distribuição percentual das atividades, tempo de ócio, tempo de pastejo, tempo de ruminação, taxa de bocados.

\begin{abstract}
The objective of this trial was to evaluate how two levels of green leaves biomass, represented by 350 and $600 \mathrm{~kg}$ ha' ${ }^{-1}$ of green leaves dry matter (GLDM) affected beef steers behaviour and its bite rate. Evaluations of ingestive behaviour were performed with focal animals observed visually on two periods of 24 hours, with beginning and end at 01 pm, during pasture growth season, at 08/16-17 and 09/24-25/2002. Three trained observers were used for each turn of six hours, one for each two contiguous paddocks (where three focal animals grazed). At 10 minutes intervals, grazing time, rumination activities and rest were registered and estimated the bite rate, as the number of apprehension bites per minute. The lower dry matter percentage existing in the pasture during the first evaluation was responsible for the higher grazing time, when comparing the periods. In the first evaluation, the activity complementary to grazing was rumination and there was not differences for rest time. The lower biomass treatment induced the steers to take more bites as a way of optimizing forage consumption.
\end{abstract}

Key words: activities percentual distribution, rest time, grazing time, rumination time, bites rate.

\section{INTRODUÇÃO}

A desfolhação por meio do corte mecânico ou pastejo do animal determina modificações

\footnotetext{
${ }^{1}$ Aluno de Graduação em Zootecnia, Universidade Federal de Santa Maria (UFSM), Bolsista do Programa Institucional de Bolsas de Iniciação Científica, Conselho nacional de Desenvolvimento Científico e Tecnológico, (PIBIC-CNPq). Av. Medianeira, 1286, apto. 801, 97060-002, Santa Maria, RS. E-mail: naime.trevisan@zipmail.com.br.

2Engenheiro Agrônomo, Professor Adjunto, Departamento de Zootecnia, UFSM. Santa Maria, RS. E-mail: fquadros@ccr.ufsm.br. ${ }^{3}$ Aluno de Graduação em Zootecnia, UFSM, Bolsista do Fundo de Incentivo à Pesquisa (FIPE).

${ }^{4}$ Aluno de Pós-graduação em Zootecnia, UFSM, Bolsista da Coordenação de Aperfeiçoamento de Pessoal de Nível Superior (CAPES).

${ }^{5}$ Aluno de Graduação em Zootecnia, UFSM, Bolsista da Fundação de Amparo à Pesquisa do Estado do Rio Grande do Sul (FAPERGS).

${ }^{6}$ Aluno de Graduação em Agronomia, UFSM.

${ }^{7}$ Aluno de Graduação em Zootecnia, UFSM.
} 
estruturais e populacionais na vegetação que acarretam reduções das superfícies foliares e, eventualmente, do número de meristemas em crescimento (MAZZANTI, 1997). A manutenção de níveis de biomassa de lâminas foliares verdes como forma de manejo de uma pastagem justifica-se no sentido de manter a maior área fotossinteticamente ativa, bem como disponibilizar aos ruminantes a fração de maior qualidade nutricional das plantas (LEMAIRE \& AGNUSDEI, 1999). Porém, a qualidade da dieta não depende somente do potencial qualitativo da pastagem, mas também da possibilidade e capacidade do animal em selecionar uma dieta de alto valor nutritivo (PRACHE \& PEYRAUD, 1997). Portanto as interações que se estabelecem entre a colheita da forragem e a biomassa disponível ao pastejo são alguns dos determinantes dos resultados nas produções de carne, leite ou lã.

A quantidade de matéria seca, principalmente a disponibilidade de folhas verdes, bem como sua distribuição espacial, afetam o tempo de permanência na busca e colheita do alimento. Considerando que as atividades dos animais são excludentes, o aumento ou a redução no tempo de pastejo implica alterações nas demais variáveis componentes do comportamento ingestivo, como o tempo de ruminação, o ócio, atividades sociais, entre outros (CARVALHO et al., 2001).

A medida da taxa de bocados estima com que facilidades ocorrem apreensões de forragem, o que, aliado ao tempo dedicado pelo animal ao processo de pastejo, bem como a profundidade e massa de bocados, integram relações planta-animal responsáveis por determinada quantidade consumida. Para a compreensão destas relações, a simples quantificação das alturas e massas de forragem não são suficientes para esclarecer todas as respostas produtivas. Desta forma, a quantificação da massa de lâminas foliares verdes, colmos e material senescente, devem ser consideradas, bem como a descrição da estrutura da pastagem e sua evolução no decorrer do tempo. Isto porque podemos encontrar a mesma massa de forragem com inúmeras combinações de altura, densidade e composição (CARVALHO et al., 1999). Assim, o objetivo deste trabalho foi avaliar como dois níveis distintos de biomassa de folhas verdes, representados por 350 e $600 \mathrm{~kg} \mathrm{ha}^{-1} \mathrm{MSFV}$ afetam o comportamento de novilhos de corte, sua taxa de bocados e a distribuição percentual das atividades de ingestão ao longo das 24 horas do dia.

\section{MATERIAL E MÉTODOS}

O experimento foi conduzido no período de maio a outubro de 2002, em área experimental do D epartamento de Zootecnia da Universidade Federal de Santa Maria, situada na região fisiográfica da Depressão Central do Rio Grande do Sul, a qual se encontra a $29^{\circ} 43^{\prime}$ de latitude Sul, $53^{\circ} 42^{\prime}$ de longitude Oeste e $95 \mathrm{~m}$ de altitude. O clima da região é subtropical úmido (Cfa), conforme a classificação de Köppen (MORENO, 1961).

O estabelecimento da pastagem ocorreu no dia $11 / 05$, por meio de semeadura direta, utilizando $84 \mathrm{~kg}$ $\mathrm{ha}^{-1}$ de sementes de aveia preta em linhas e $40 \mathrm{~kg} \mathrm{ha}^{-1}$ de sementes de azevém a lanço. Em virtude da baixa germinação das sementes de azevém realizou-se nova semeadura deste no dia 25/05, com $25 \mathrm{~kg} \mathrm{ha}^{-1}$ de sementes. A adubação de base ocorreu por ocasião da semeadura da aveia, com auxílio de uma semeadoraadubadora, utilizando-se $200 \mathrm{~kg} \mathrm{ha}^{-1}$ da fórmula 05-2020 (NPK). Em cobertura, utilizaram-se $100 \mathrm{~kg} \mathrm{ha}^{-1} \mathrm{de} \mathrm{N}$, na forma de uréia, divididos em duas aplicações, nos dias 20/06 e 12/08.

Utilizou-se uma área de 5,4ha, divididos em seis potreiros com área média de 0,7ha, e um potreiro com cerca de 1,2ha para permanência dos animais reguladores. Os tratamentos foram os níveis de biomassa de lâmina foliar verde, de 350 e $600 \mathrm{~kg}$ $\mathrm{ha}^{-1}$ de $\mathrm{MS}$, com duas e quatro repetições, respectivamente. $\mathrm{O}$ delineamento experimental utilizado foi o inteiramente casualisado. $O$ método de pastejo foi contínuo, com taxa de lotação variável, conforme metodologia proposta por MOTT \& LUCAS (1952).

Para as avaliações de comportamento ingestivo, foi utilizado o método direto de observação visual (HUGHES \& REID, 1951) dos 18 animais focais devidamente identificados, os quais possuíam idade e peso médio inicial de nove meses e $175 \mathrm{~kg}$. Realizaramse dois períodos de 24 horas de observação das atividades dos animais, com início e término às 13:00 horas, nos dias 16-17/08 e 24-25/09. Para cada turno de seis horas, eram utilizados três observadores treinados, um para cada dois potreiros (cada potreiro comportava três animais focais). A cada 10 minutos, foram registradas as atividades de pastejo (TP), ruminação (TR) e ócio (TO). Conforme CASTRO (2002), o tempo de pastejo representa o período em que o animal está ativamente apreendendo ou selecionando forragem. O tempo de ruminação é considerado como o período em que o animal não está pastejando, entretanto, está mastigando o bolo alimentar retornado do rúmen. Este tempo é observado pelo movimento da boca do animal. O tempo de ócio representa o período em que o animal não está pastejando, nem tampouco ruminando. Aqui estão incluídos os tempos de ingestão de água, atividades sociais, entre outros. 
As temperaturas mínimas verificadas nos dias 16-17/08 e 24-25/09 foram de 12,4 e 7,2 ${ }^{\circ} \mathrm{C}$, respectivamente, e as temperaturas máximas de 26,8 e $24,4^{\circ} \mathrm{C}$. As médias de insolação corresponderam a quatro horas e 26 minutos e 10 horas e 12 minutos para o primeiro e segundo períodos, respectivamente.

Para a medida da taxa de bocados, foi escolhido, aleatoriamente, um animal focal por potreiro, considerando que cada potreiro constitui uma repetição dos tratamentos. Procederam-se estimativas visuais, medindo-se o tempo que o animal leva para completar 20 bocados de apreensão (FORBES \& HODGSON, 1985), em intervalos de 10 minutos sempre que fosse verificada atividade de pastejo. Após, este valor era transformado para número de bocados por minuto.

Os valores registrados para as variáveis de comportamento observadas foram processados em uma planilha do Microsoft Excel, através do somatório dos tempos de pastejo, ruminação e ócio. Para cada período de 24 horas, foi calculada a taxa média de bocados.

As análises estatísticas utilizaram a rotina de testes de aleatorização do programa MULTIV
(PILLAR, 1997). Sendo analisados os efeitos de tratamento, período e suas interações.

\section{RESULTADOS E DISCUSSÃO}

O tempo diário de pastejo, ruminação e ócio, em minutos por dia, e a taxa de bocados, em número de bocados por minuto, por períodos de 24 horas e suas médias ponderadas, são apresentados na tabela 1 .

Foi registrado um maior tempo com a atividade de pastejo, para a média dos tratamentos, na primeira avaliação $(\mathrm{P}<0,15)$, o que pode ser parcialmente justificado pela menor porcentagem de matéria seca existente na pastagem durante este período. MONTOSSI (2003) demonstra que a curva de crescimento e desenvolvimento das plantas vem acompanhada de mudanças em sua estrutura morfológica e química. No estádio de desenvolvimento inicial, existem altas concentrações de carboidratos solúveis e baixas de carboidratos estruturais. Esta situação aumenta a velocidade de passagem do material ingerido pelo trato gastro-intestinal, permitindo o prolongamento das atividades de ingestão.

Os tratamentos provavelmente proporcionaram uma capacidade de seleção pela fração

Tabela 1 - Tempo diário (minutos.dia- ${ }^{1}$ ) de pastejo, ruminação e ócio e taxa de bocados (número de bocados.minuto-1) por período de 24 horas e média ponderada, de novilhos de corte em pastagem cultivada de aveia preta e azevém submetida a diferentes níveis de biomassa de lâmina foliar verde.

\begin{tabular}{|c|c|c|c|}
\hline \multirow{3}{*}{$\begin{array}{l}\text { Tratamentos } \\
\left(\mathrm{kg} \mathrm{ha-}{ }^{-1} \text { de MSFV) }\right.\end{array}$} & \multicolumn{2}{|c|}{ Períodos } & \multirow{3}{*}{ Média } \\
\hline & 16 a $17 / 08 / 02$ & 24 a $25 / 09 / 02$ & \\
\hline & \multicolumn{2}{|c|}{ Tempo diário de pastejo } & \\
\hline 350 & $618,33 \mathrm{a}$ & $476,67 \mathrm{~b}$ & 547,50 \\
\hline 600 & $531,67 \mathrm{~b}$ & $531,67 \mathrm{a}$ & 531,67 \\
\hline \multirow[t]{2}{*}{ Média } & $575 \mathrm{a}$ & $504,17 \mathrm{~b}$ & \\
\hline & \multicolumn{2}{|c|}{ Tempo diário de ruminação } & \\
\hline 350 & $408,33 \mathrm{~b}$ & 476,67 & $442,50 \mathrm{~B}$ \\
\hline 600 & 496,67 a & 472,50 & $484,59 \mathrm{~A}$ \\
\hline \multirow[t]{2}{*}{ Média } & 452,50 & 474,59 & \\
\hline & \multicolumn{2}{|c|}{ Tempo diário de ócio } & \\
\hline 350 & 413,33 & 486,67 & 450,00 \\
\hline 600 & 411,67 & 435,83 & 423,75 \\
\hline \multirow[t]{2}{*}{ Média } & 412,50 & 461,25 & \\
\hline & \multicolumn{2}{|c|}{ Taxa de bocados } & \\
\hline 350 & 50,77 & 66,40 & $58,59 \mathrm{~A}$ \\
\hline 600 & 47,69 & 62,26 & $54,98 \mathrm{~B}$ \\
\hline Média & 49,23 & 64,33 & \\
\hline
\end{tabular}

Letras minúsculas distintas na mesma coluna diferem entre si $(\mathrm{P}=0,049)$.

Letras minúsculas distintas em negrito na mesma linha indicam diferença entre as médias $(\mathrm{P}=0,15)$.

Letras maiúsculas distintas na mesma coluna diferem entre si $(\mathrm{P}=0,077)$.

Letras maiúsculas distintas em negrito na mesma coluna indicam diferença entre as médias $(\mathrm{P}=0,158)$.

Ciência Rural, v.34, n.5, set-out, 2004. 
folhas, permitindo que o tempo de ruminação não se alterasse de forma significativa.

Existe um consenso de que a massa residual de forragem para as consorciações de espécies de estação fria deva estar situada na faixa de 1200 a $1600 \mathrm{~kg}$ ha $^{-1}$ de matéria seca (MS) para que não ocorram limitações na produção animal (COSER et al., 1981; MOTT, 1984; FLOSS, 1988). Neste experimento, procurou-se redefinir a estrutura desta massa de forragem, pois é conhecida a preferência dos ruminantes pela fração folha, devido, principalmente à maior digestibilidade e velocidade de passagem pelo trato gastro-intestinal (ABRAHÃO, 1996). Como média, registrou-se ao redor de $50 \%$ de folhas em comparação aos demais componentes das plantas. Os tratamentos de 350 e $600 \mathrm{~kg} \mathrm{ha}^{-1}$ de matéria seca de folhas verdes (MSFV), estiveram, portanto, representando, aproximadamente, uma massa residual de 650 e $1250 \mathrm{~kg} \mathrm{ha}^{-1}$ de MS, respectivamente.

No tratamento de menor biomassa de folhas verdes, esperava-se que o tempo despendido pelos animais à colheita de forragem fosse maior em comparação ao outro tratamento. Isto porque o aumento do tempo de pastejo é uma estratégia que os animais dispõem para tentar compensar a diminuição da massa do bocado em situações de baixa disponibilidade de forragem (LACA et al., 1992; ARMSTRONG et al., 1995). Este fato realmente aconteceu no primeiro período. Atribui-se a inversão deste comportamento, no segundo período, ao final do ciclo vegetativo da aveia, representando maior formação de áreas de exclusão de pastejo nos potreiros mantidos com alta biomassa, obrigando os animais a dedicarem maior tempo na busca por estações alimentares preferidas (TREVISAN et al., 2003). Nos potreiros de baixa biomassa, os colmos de aveia mantiveram-se baixos desde o início do experimento, o que facilitou o acesso às folhas de azevém e permitiu que o tempo de pastejo fosse menor. FREITAS et al., (2002) trabalhando com massas de forragem de $1500 \mathrm{e}$ $1200 \mathrm{~kg} \mathrm{ha}^{-1} \mathrm{MS}$ registraram 592,3 e 447,4minutos dia-1, respectivamente, como tempo dedicado à atividade de pastejo de novilhas de corte em pastagem de aveia e azevém. Observa-se que, no tratamento de alta massa de forragem, o tempo de pastejo foi $23 \%$ superior ao tratamento de $1200 \mathrm{~kg} \mathrm{ha}^{-1} \mathrm{MS}$. Os autores atribuem este fato à maior porcentagem de colmos de aveia encontrados no tratamento de $1500 \mathrm{~kg} \mathrm{ha}^{-1} \mathrm{MS}$. Este fato coincide com o observado nos potreiros de alta biomassa deste experimento.

O tempo de pastejo encontrado nos níveis de 350kg ha-1 e 600kg ha-1 MSFV, de 547,50 e 531,67minutos $\mathrm{dia}^{-1}$, respectivamente, encontra-se na faixa de 485 a 609,7minutos dia $^{-1}$ registrados por SILVEIRA(2001) com o pastejo de ovinos em azevém anual.

O tempo que os animais do tratamento de $350 \mathrm{~kg} \mathrm{ha}^{-1} \mathrm{MSFV}$ permaneceram em ócio é semelhante aos observados por GENRO et al. (2002) de 450minutos $\mathrm{dia}^{-1}$ com novilhas de corte em pastagem de aveia e azevém. A atividade complementar ao pastejo na primeira avaliação foi a ruminação para os dois tratamentos, sem diferenças para ócio.

As médias de taxa de bocados apresentadas na tabela 1 demonstram que a mais baixa biomassa obrigou os animais a aumentarem o número de bocados como forma de otimizar o consumo de forragem. Os valores semelhantes para ganho médio diário observados por SILVA et al. (2003), correspondentes a 0,830 e $0,993 \mathrm{~kg}$ animal $\mathrm{dia}^{-1}$, para os tratamentos de baixa e alta biomassa de folhas verdes, respectivamente, reforçam a hipótese de que esta compensação foi atingida. Porém esta explicação não encontra respaldo com as afirmações propostas por ALLDEN \& WHITTAKER (1970) e, mais recentemente, por PENNIG (1986) de que a baixa massa de bocados obtida nas menores alturas da pastagem não poderia ser adequadamente compensada pelo aumento do número de bocados.

A distribuição percentual das atividades, na primeira avaliação do comportamento ingestivo, demonstra que o pico de pastejo concentrou-se das 06:00 às 18:00 horas para os dois tratamentos (Figura 1). Dentro deste período, o pastejo acentua-se, pela manhã, das 07:00 às 09:00 e, pela tarde, das 16:00 às 18:00 horas. A atividade de ruminação concentra-se, principalmente das 24:00 às 06:00 horas. Na segunda avaliação, a atividade de ruminação encontra-se mais uniformemente distribuída durante a noite, e os mesmos picos de pastejo são verificados (Figura 2). Este

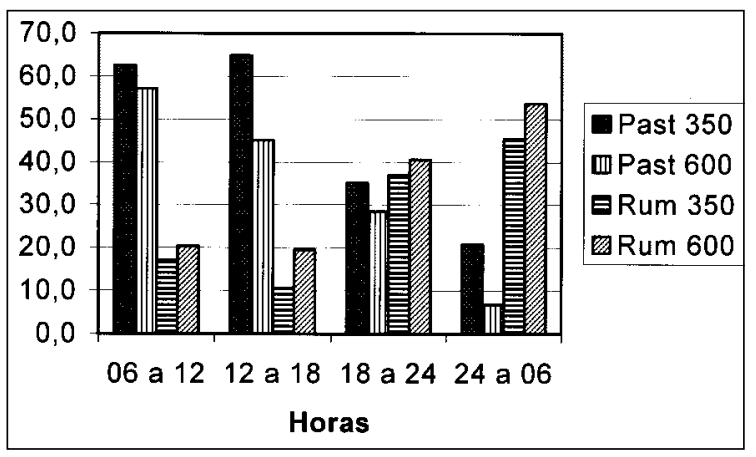

Figura 1 - Distribuição percentual das atividades de pastejo (Past) e ruminação (Rum) de novilhos de corte em pastagem de aveia preta e azevém sob níveis de biomassa de lâminas foliares verdes de 350 e $600 \mathrm{~kg} \mathrm{ha}^{-1}$ nas datas de 16-17/08/2002.

Ciência Rural, v.34, n.5, set-out, 2004. 


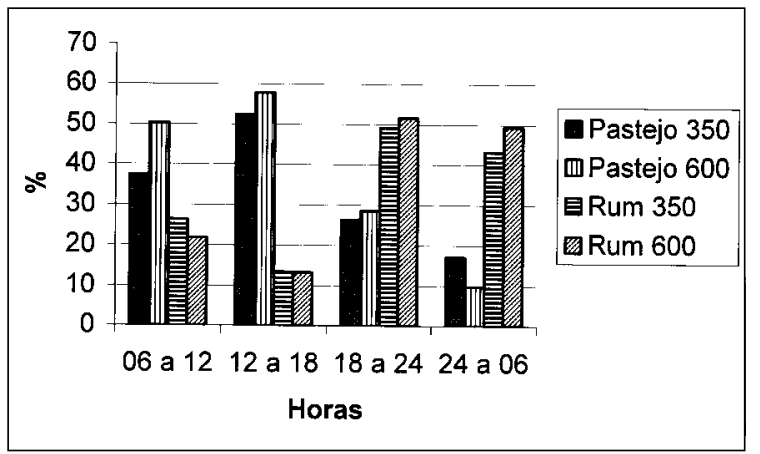

Figura 2 - Distribuição percentual das atividades de pastejo e ruminação (Rum) de novilhos de corte em pastagem de aveia preta e azevém sob níveis de biomassa de lâminas foliares verdes de 350 e $600 \mathrm{~kg} \mathrm{ha}^{-1}$ nas datas de 24-25/09/2002.

comportamento está de acordo com os horários descritos por ARNOLD \& DUDZINSKI (1978) como sendo os períodos do dia de maior freqüência de pastejo.

\section{CONCLUSÕES}

A manutenção de níveis baixos de biomassa permite melhor acesso às folhas de azevém dispostas nos extratos inferiores, proporcionando menor tempo de pastejo dos animais deste tratamento. O comportamento ingestivo dos animais pode ser afetado por níveis baixos de biomassa de lâminas foliares, forçando-os a aumentarem o número de bocados como forma de otimizar o consumo de forragem.

\section{REFERÊNCIAS BIBLIOGRÁFICAS}

ABRAHÃO, J.J.S. Valor nutritivo de plantas forrageiras. Londrina, PR : Forragicultura no Paraná, 1996. 305p. p.93108 .

ALLDEN, W.G.; WHITTAKER, M.C. The determinants of herbage intake by grazing sheep: The Interrelationship of factors influencing herbage intake and availability. Australian Journal of Agricultural Research, Victoria, v.21, p.755766,1970

ARMSTRONG, R. H. et al. The effect of sward height and its direction of change on herbage intake. Diet selection and performance of weaned lambs grazing ryegrass swards. Grass and Forage Science, Oxford, v.58, p.389-398, 1995.

ARNOLD, G.W., DUDZINSKI, M.L. Ethology of free-ranging domenstic animals. Netherlands : ESPC, 1978. 198p.

CARVALHO, P.C.F. et al. Importância da estrutura da pastagem na ingestão e seleção de dietas pelo animal em pastejo. A produção animal na visão dos brasileiros. Piracicaba : FEALQ, 2001. p.853-871.
CARVALHO, P.C.F.; PRACHE, S.; DAMASCENO, J.C. O processo de pastejo: desafios da procura e apreensão da forragem pelo herbívoro. In: REUNIÃO ANUAL DA SOCIEDADE BRASILEIRA DE ZOOTECNIA, 36., 1999, Porto Alegre. Anais... Porto Alegre-RS: SBZ, 1999. V.2, p. 253-268.

CASTRO, C.R.C. Relações planta-animal em pastagem de milheto (Pennisetum americanum (L.) leeke.) manejada em diferentes alturas com bovinos. 2002. $185 \mathrm{f}$. Dissertação (Mestrado em Zootecnia) - Curso de Pósgraduação em Zootecnia, Universidade Federal do Rio Grande do Sul. Porto Alegre, 2002.

COSER, A.C.; CARVALHO, L.A.; GARDNER, A.L. Desempenho de animais em aveia sob pastejo contínuo. Coronel Pacheco, MG : EMBRAPA, Centro Nacional de Pesquisa de Gado de Leite, 1981. p.9. (Circular técnica n. 10).

FLOSS, E.L. Manejo forrageiro de aveia (Avena $\mathbf{S p )}$ e azevém (Lolium Sp). In: SIMPÓSIO SOBRE MANEJO DA PASTAGEM, 9., 1988. Piracicaba. Anais... Piracicaba : FEALQ, 1988. 358p.

FORBES, T.D.A.; HODGSON, J. Comparative studies of the influence of sward conditions on the ingestive behaviour of cows and sheep. Grass and Forage Science, Oxford, v.40, p.69-77, 1985.

FREITAS, F.K. et al. Tempo de pastejo de novilhas de corte em pastagem cultivada. In: REUNIÓN DE GRUPO TÉCNICO EN FORRAJERAS DEL CONO SUR, 19., 2002, Mercedes. Anais... Mercedes : INTA, 2002. p.179-180.

GENRO, T.C.M. et al. Comportamento ingestivo de terneiras em pastejo recebendo ou não suplementação. In: REUNIÓN DE GRUPO TÉCNICO EN FORRAJERAS DEL CONO SUR, 19., 2002, Mercedes. Anais... Mercedes : INTA, 2002. p.203204

HUGHES, G.P.; REID, D. Studies on the behavior of cattle and sheep in relation to utilization of grass. Journal Agricultural Science, v.41, p.350-355, 1951.

LACA, E.A. et al. Effectes of sward height and bulk density on bite dimensions of cattle grazing homogeneous swards. Grass and Forage Science, Oxford, v.47, p.91-102, 1992 .

LEMAIRE, G.; AGNUSDEI, M. Leaf tissue turn-over and efficiency of herbage utilisation. In: SIMPÓSIO INTERNACIONAL "GRASSLAND ECOPHYSIOLOGY AND GRAZING ECOLOGY", 1999, Curitiba. Anais... Curitiba : UFPR, 1999. p.165-186.

MAZZANTI, A. Adaptación de especies forrajeras a la desfoliación. In: SIMPÓSIO SOBRE AVALIAÇÃO DE PASTAGENS COM ANIMAIS, 1997, Maringá. Anais... Maringá : UEM, 1997. p.75-84.

MONTOSSI, F. Utilização de pastagens em sistemas pecuários (Utilización e mejoramientos de campo em pastoreo mixto para engorde de novillos y corderos en Uruguay). In: REUNIÃO ANUAL DA SOCIEDADE BRASILEIRA DE ZOOTECNIA, 40., 2003, Santa Maria. Anais... Santa Maria, RS : Sociedade Brasileira de Zootecnia, 2003. (CD-ROOM). 
MOREno, J.A. Clima do Rio Grande do Sul. Porto Alegre: Secretaria da Agricultura, 1961. 41p

MOTT, G.O. Relationship of available forage and animal performance in tropical grazing systems. In: FORRAGE GRASSLAND CONFERENCE, 1984, Houston, Texas. Proceedings... Lexington : American Forage and Grassland Council, 1984. p.373-377.

MOTT, G.O.; LUCAS, H.L. The design conduct and interpretation of grazing trials on cultivated and improved pastures. In: INTERNACIONAL GRASSLAND CONGRESS, Pensylvania, 6., 1952. Proceedings... Pensylvania : State College, 1952. p.1380-1395.

PENNING, P.D. Some effects of sward conditions on grazing behaviour and intake by sheep. In: GUDMUNDSSUN, O. Grazing Research and Nothern Latitudes. [S.I.: s.n.], 1986. p.219-226.

PILLAR, V.D.P. Multivariate exploratory analysis and randomization testing with MULTIV. Coenoses, Gorizia, v.12, p.145-148, 1997.

PRACHE, S.; PEYRAUD, J. Préhensiblite de I’ herbe pâturée chez lês bovins et lês ovins. INRA Productions Animales, [Paris], v.10, p.377-390, 1997.

SILVA, A.C.F. et al. Produção animal em pastagem de aveia preta mais azevém sob diferentes níveis de biomassa de lâmina foliar verde. In: REUNIÃO ANUAL DA SOCIEDADE BRASILEIRA DE ZOOTECNIA, 40., Santa Maria. Anais... Santa Maria, RS : Sociedade Brasileira de Zootecnia, 2003. (CD-ROOM).

SILVEIRA, E.O. Produção e comportamento ingestivo de cordeiros em pastagem de azevém anual (Lolium multiflorum Lam.) manejada em diferentes alturas. 2001. 250f. Dissertação (Mestrado em Zootecnia)- Programa de Pós-graduação em Zootecnia, Faculdade de Agronomia, Universidade Federal do Rio Grande do Sul.

TREVISAN, N.B. et al. Tempo de permanência por estação alimentar e distância entre estações de pastejo em pastagem de aveia preta e azevém submetida a diferentes níveis de biomassa de lâmina foliar verde. In: REUNIÃO ANUAL DA SOCIEDADE BRASILEIRA DE ZOOTECNIA, 40., 2003, Santa Maria. Anais... Santa Maria, RS : Sociedade Brasileira de Zootecnia, 2003. (CD-ROOM). 